\title{
Development of an Inventory of Coastal Wetlands for Eastern Georgian Bay, Lake Huron
}

\author{
Jonathan Midwood, Daniel Rokitnicki-Wojcik, and Patricia Chow-Fraser \\ Department of Biology, McMaster University, 1280 Main Street West, Hamilton, ON, Canada L8S 4K1 \\ Correspondence should be addressed to Jonathan Midwood, midwoojd@mcmaster.ca
}

Received 5 December 2011; Accepted 11 January 2012

Academic Editors: T. Muotka and S. Sabater

Copyright ( $) 2012$ Jonathan Midwood et al. This is an open access article distributed under the Creative Commons Attribution License, which permits unrestricted use, distribution, and reproduction in any medium, provided the original work is properly cited.

\begin{abstract}
Coastal wetlands of eastern Georgian Bay provide critical habitat for a variety of wildlife, especially spawning and nursery habitat for Great Lakes fishes. Although the eastern shoreline has been designated a World Biosphere Reserve by UNESCO, a complete inventory is lacking. Prior effort by the Great Lakes Coastal Wetland Consortium (GLCWC) was unable to fully identify coastal wetland habitat in eastern Georgian Bay due to limited data coverage. Here we outline the methodology, analyses, and applications of the McMaster Coastal Wetland Inventory (MCWI) created from a comprehensive collection of satellite imagery from 2002 2008. Wetlands were manually delineated in a GIS as two broad habitat types: coastal marsh and upstream wetland. Coastal marsh was further subdivided into low marsh (LM; permanently inundated) and high marsh (HM; seasonally inundated) habitat. Within the coastal zone of eastern and northern Georgian Bay there are 12629 distinct wetland units comprised of 5376 ha of LM, 3298 ha of HM and 8676 ha of upstream habitat. The MCWI identifies greater total wetland area within the coastal zone than does the GLCWC inventory (17350 ha versus 3659 ha resp.). The MCWI provides the most current and comprehensive inventory of coastal wetlands in eastern Georgian Bay.
\end{abstract}

\section{Introduction}

Wetlands represent some of the most biologically diverse ecosystems on the planet, yet globally, estimates of wetland loss due to human development range from $50 \%$ to $90 \%$ [1]. Canada has approximately $25 \%$ of the world's wetlands $[2,3]$. As a signatory in 1981 of the Ramsar convention, Canada has an obligation to identify and protect ecologically important wetlands (http://www.ramsar.org/). To date, Canada has protected more wetland area than any other country, but the prevalence of wetlands in the Canadian landscape means that there are many wetlands that have not yet been delineated. In many regions of Canada, there is still an urgent need to catalogue and monitor wetlands [3].

The Laurentian Great Lakes, shared by Canada, and the United States, represent the largest freshwater resource in the world. A review of wetland research conducted in this region by Herendorf [4] identified over 1500 large coastal wetlands with a total surface area of $1700 \mathrm{~km}^{2}$. These marshes provide many important ecosystem services including water purification, nutrient sequestration, and shoreline buffering $[1,3]$, as well as important feeding and nursery habitat for a wide variety of organisms including fish, birds, invertebrates, mammals, and reptiles [5-7]. In Ontario, majority of these wetlands have been lost or degraded as a result of human disturbance [8], except in the eastern and northern shore of Georgian Bay, where they are mostly in relatively pristine condition [9].

During the early 2000s, the Great Lakes Coastal Wetland Consortium (GLCWC) [10], consisting of both US and Canadian scientists and policy makers, worked together to create a Geographic Information Systems (GISs) inventory for all five Great Lakes. The GLCWC aimed to delineate all coastal wetlands along the Great Lakes shoreline that were $>2$ ha in size. The Consortium included all wetlands in the Ontario Great Lakes Coastal Wetland Atlas (OGLCWA) [11], which is a GIS atlas of all wetlands that had been evaluated by the Ontario Ministry of Natural Resources using the Ontario Wetland Evaluation System (OWES) [12]; information used in this atlas dated back to 1983 
and were updated with information current to 1999. The OGLCWA was complete for Lakes Superior, Erie, Ontario, as well as all connecting channels, but was incomplete for Lake Huron because it was missing some large wetlands occurring in eastern and northern Georgian Bay. Therefore, the Consortium employed experts to manually identify wetlands using available aerial photographs for this region. For eastern Georgian Bay, aerial photographs (taken in the summers between 1984 to 2000) were available at a scale of 1:10000 from Severn Sound to Parry Sound, and this allowed for a pixel resolution of $0.4 \mathrm{~m}$. From Parry Sound to Key River, however, photos were only available at a scale of $1: 20000$ (taken in the summers between 1986 to 1996) and allowed for a more coarse pixel resolution of $0.8 \mathrm{~m}$. There was only limited coverage of aerial photos for northern Georgian Bay from the Key River to MacGregor Bay.

Lack of information along the shore and in the surrounding islands of eastern Georgian Bay is a serious concern because this region holds some of the most pristine coastal marshes in the entire Great Lakes basin $[9,13]$. This area is unique due to the low levels of agriculture and urban development that have allowed these wetlands to maintain the highest proportions of disturbance-intolerant fish and plant taxa within the Great Lakes coastal system [9, 13-15]. Although much of the shoreline was logged prior to the 1900s, easier access to inland logging sites and slow successional growth have prevented continuous logging along the shoreline in the past century. Hence, most of the wetlands have been able to persist in relatively natural condition, free of human disturbance. Furthermore, watersheds of eastern and northern Georgian Bay have thin, nutrient-poor soils on top of Precambrian Shield, which has created naturally oligotrophic coastal wetlands with very soft water mixed with more alkaline water of Georgian Bay [16]; this creates unique geochemical characteristics that support regionally high biodiversity of aquatic plants [17]. Lastly, the complex shoreline of eastern Georgian Bay is composed of both large riverine wetlands as well as thousands of small ( $<2$ ha) shallow rocky embayments which are protected from the strong wind and wave action that characterize the region. Therefore, Georgian Bay has an assembly of coastal wetlands that are unique in the Great Lakes basin in terms of geochemistry, biodiversity, areal cover, and abundance and can be considered reference conditions for the Great Lakes [18].

Besides the ubiquitous potential for indiscriminate human development [16], coastal wetlands of Georgian Bay have been strongly influenced by the sustained low water levels that have prevailed over the last decade (Figure 1). This trend is expected to continue, with climate change scenarios predicting a further decline in water level of Lakes Huron-Michigan by $>1 \mathrm{~m}$ during the next 25 years [19], accompanied by reduced interannual variation [20]. Coastal wetlands are dynamic systems, where diversity of habitat and biota are maintained by a natural disturbance in the form of fluctuating water levels; in years of high water, terrestrial vegetation dies back, and, in years of low water levels, aquatic vegetation dies back [21]. Without interannual water-level variation, either the aquatic or the terrestrial vegetation would dominate at the expense of the other. The current episode of sustained low water levels would favour terrestrial vegetation at the expense of aquatic vegetation [22], which is an important component that provides critical spawning and nursery habitat for the Lake Huron fish community [23, 24].

Although water levels encountered presently are not the lowest in recorded history for Lakes Huron-Michigan, the sustained low water levels that began in 2001 and that have persisted through to 2011 have not occurred in the last 100 years, and it is difficult to predict how the wetland community will adapt to these extremes, and how the fish community, in particular, will be able to adjust to losses and gains in aquatic habitat. Hence, there is an urgent need to conduct research to determine how this trend towards lower water levels will affect the quantity and quality of wetland habitat so that they can be monitored and protected from further human activities. To aid environmental agencies and municipal planners and to enable valid extrapolation, it is important that the research be conducted on a set of randomly chosen wetlands. To date, however, there is no such inventory, because the one created by the GLCWC is incomplete for this region. There are other limitations of the GLCWC inventory (herein GLCWCI) that make it unsuitable for research on fish habitat. First, since wetlands have been delineated from photos taken in different years (1983 to 1999) and at different water levels, size of habitat zones in wetlands within the inventory cannot be directly compared because they are not standardized to one water level. Secondly, the GLCWCI excludes most of the wetlands that occur in the rocky coastal region and island archipelagos of northeastern Georgian Bay, where there could be extensive fish habitat. The last and perhaps the greatest limitation for fish ecologists is that the inventory does not distinguish between terrestrial and aquatic habitat types and it is impossible to determine the distribution of fish habitat across the region.

In this paper, we show how a comprehensive coastal wetland inventory can be created for eastern and northern Georgian Bay that is both cost-effective and suitable for use in studies of fish habitat at the scale of the entire Georgian Bay (over $4500 \mathrm{~km}$ of shoreline). We propose to use highresolution IKONOS satellite imagery acquired during a 5year period with similar water levels to ensure that wetland habitat can be directly comparable across the region and to limit the inconsistencies that can result when imagery under different water-level scenarios are used to delineate wetlands boundaries. We will also apply a simple rule to delineate coastal wetland habitat into low-marsh zone (fish habitat) and high-marsh zone (meadow habitat). The approach we develop here can be used in coastal projects of other large lakes where there is a need to monitor changes in fish habitat at a scale of an entire lake basin.

\section{Methods}

2.1. Satellite Imagery. IKONOS satellite images covering all of eastern Georgian Bay and parts of the North Channel were acquired by Georgian Bay Forever (GBF; http:// www.georgianbayforever.org/) and licensed to McMaster 


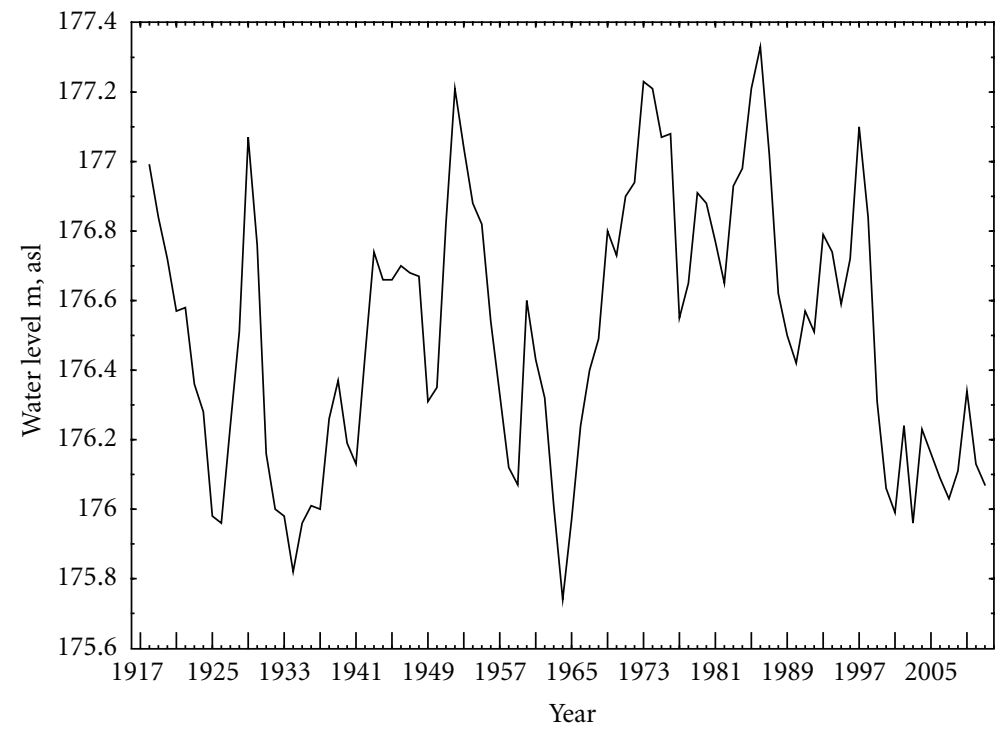

Figure 1: Change in water levels of Lake Huron from 1918 to 2011 (data from the Canadian Hydrographic Service, Department of Fisheries and Oceans).

University. Images covering the regions between Severn Sound and Parry Sound were acquired in July 2002, images covering up to Key River were acquired in July 2003, images covering the McGregor Bay and Bay of Islands regions were collected in July 2005, an image covering Matchedash Bay was collected in September 2005, and an image covering Beaverstone Bay was acquired in August 2008 (Figure 2). The IKONOS satellite images used for this inventory have a pan-sharpened resolution of $1 \mathrm{~m}$ and provide spectral information in the red, green, blue, and near-infrared wavelengths. IKONOS satellite images were not available for two regions of northern Georgian Bay, but through the Ontario Provincial QuickBird Project (2007), we were able to obtain QuickBird satellite coverage for all of the remaining gaps except for only a $10 \mathrm{~km}$ stretch between the French River and Beaverstone Bay (Figure 2). Like IKONOS imagery, QuickBird images provide high-resolution $(60 \mathrm{~cm})$ multispectral data (visible and near-infrared spectrum). In total, 8 QuickBird images were used, all of which were acquired in September 2006. In a comparison of IKONOS and QuickBird images for the purpose mapping mangroves, Wang et al. [25] found little difference in their ability to map this habitat type. We therefore concluded that the use of different image types would have a negligible impact on the quality of the final inventory.

2.2. Manual Delineation. The McMaster Coastal Wetland Inventory (MCWI) was created by manually delineating wetlands from satellite images in a GIS. The IKONOS images were initially stacked for easier use. The three visible bands (red, green, blue) of the IKONOS images were used to create a true colour image. A second image was then created through the substitution of the near-infrared (NIR) band in place of the red band (i.e., NIR, green, blue). QuickBird images were already combined into both a true colour and a near-infrared form. The NIR wavelength is a good indicator of vegetation, especially in aquatic systems [26], and, by switching between the true colour and the near-infrared images, technicians are better able to discriminate wetland vegetation from surrounding land cover. Stacked images were then imported into ArcMap 9.2 (ESRI Inc., Redlands, California, USA, 2006) in the working projection Universal Transverse Mercator (UTM), zone 17. For each wetland, the technicians traced the boundary of wetland habitats (i.e., low marsh, high marsh, upstream wetland) following specific rules regarding the upper and lower limits of each category (outlined below). The result was a single polygon for each applicable wetland category for each wetland.

2.3. Rules for Delineations/Accuracy Assessment. The Ontario Ministry of Natural Resources (OMNR) in its Ontario Wetland Evaluation Systems (OWES) [12] defines coastal wetlands as wetlands that are influenced by large water bodies and generally found within $2 \mathrm{~km}$ of the high water mark. The coastal zone is therefore operationally defined as land within $2 \mathrm{~km}$ of the shoreline and within this zone, only wetlands that are hydrologically connected via surface water to Georgian Bay are considered coastal wetlands. This $2 \mathrm{~km}$ coastal zone equates to roughly 177000 ha along the shores of eastern and northern Georgian Bay. Since the major focus of this inventory is to quantify fish habitat, surface hydrologic connectivity is an essential criterion. Despite the existence of many hydrologically isolated wetlands upstream of the shoreline, disconnected wetlands were not included. These wetlands occur above the high-water mark, and therefore they do not serve as current or potential Great Lakes coastal fisheries habitat. They also can be difficult to identify visually because they exist along a continuum of succession from open water to areas that are fully forested, and their delineation would have greatly prolonged the time 


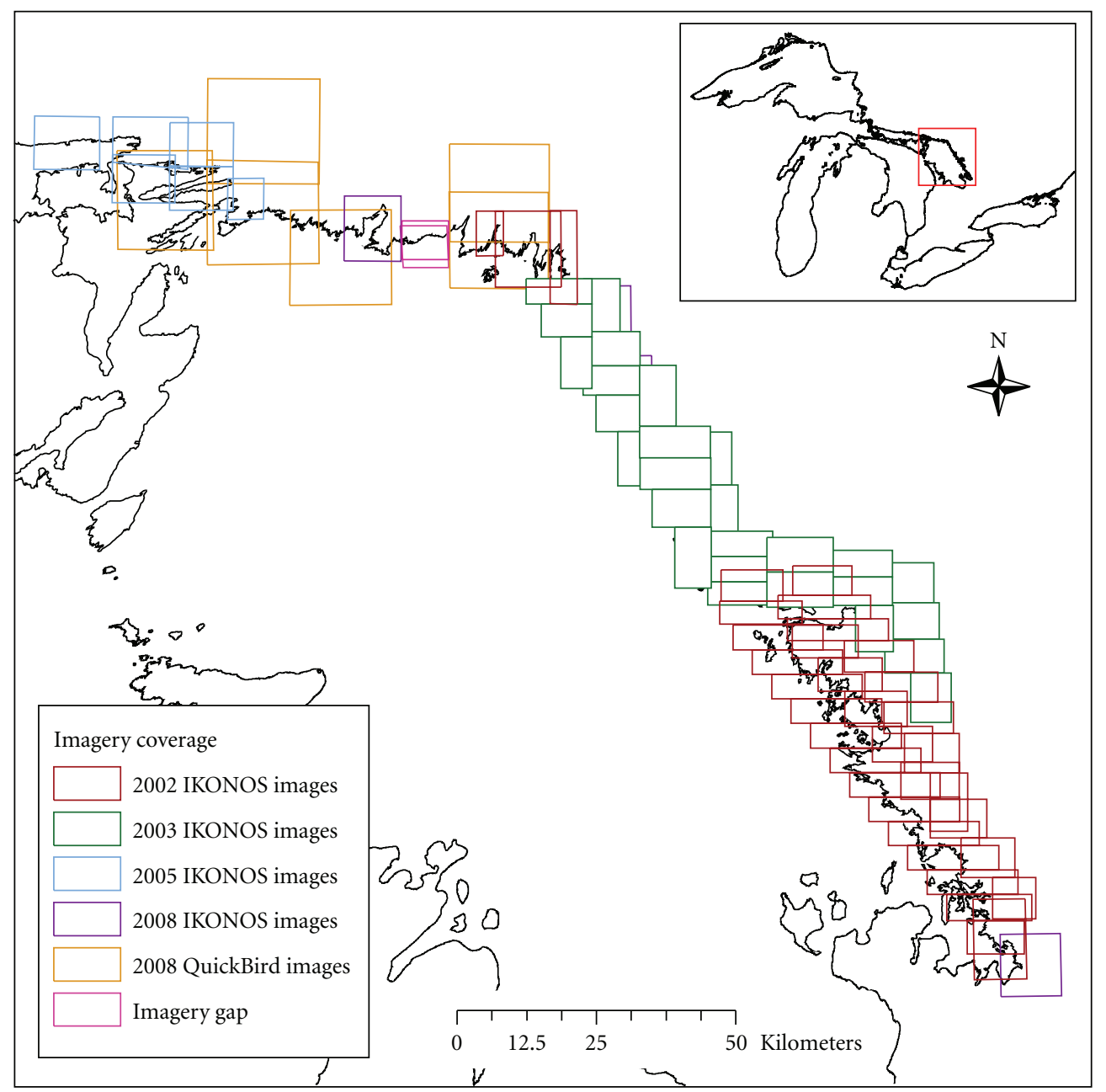

FIGURE 2: Boundaries of the satellite imagery for eastern and northern Georgian Bay acquired for this project in 2002, 2003, 2005, and 2008. To complete the coverage of northern Georgian Bay, it was necessary to acquire six QuickBird images (indicated in orange). One gap still exists along the northern shore of Georgian Bay as indicated (in pink).

to completion of the MCWI inventory. They were thus omitted from this inventory.

Each wetland found to be within $2 \mathrm{~km}$ and hydrologically connected to Georgian Bay was delineated into three habitat categories (i.e., high marsh, low marsh, upstream wetland), and the area of each polygon was calculated in ArcMap 9.2 (ESRI Inc., Redlands, California, USA, 2006). Rules for delineating boundaries of each habitat category are as follows.

(i) The high-marsh (HM) category represented wetland habitat that was inundated on a seasonal basis; this area is often referred to as "wet meadow" habitat. Wet meadows provide important habitat for a variety of species including birds, reptiles, and amphibians [27]. The lower limit of the HM habitat was defined by the shoreline and was the upper limit of LM. The upper limit of the HM was the forest boundary and/or when there was change from HM to upstream habitat (swamp, bog, or fen). (ii) The low-marsh (LM) category represented portions of the wetland that were permanently inundated and essential areas for fish spawning and foraging. Upper limits of LM habitat were defined by the water's edge and exclude meadow vegetation. The lower limit of the wetland includes submerged aquatic vegetation (SAV), which is a critical component of fish habitat. Unfortunately, the dystrophic conditions of the water in most regions of eastern Georgian Bay did not allow us to map SAV using satellite images. Therefore, the lower limit was approximated by calculating a distance that is 2.5 times the width of the emergent and/or floating vegetation zone (visible in the image) and applying this from the water's edge along the longest axis of the wetland. This distance was reduced if the lower limit extended beyond the opening of an embayment. This lake-ward boundary is considered a conservative estimate of the maximum depth of colonization by SAV, based on dozens of underwater surveys in wetlands in this region (Midwood pers. obs.). 


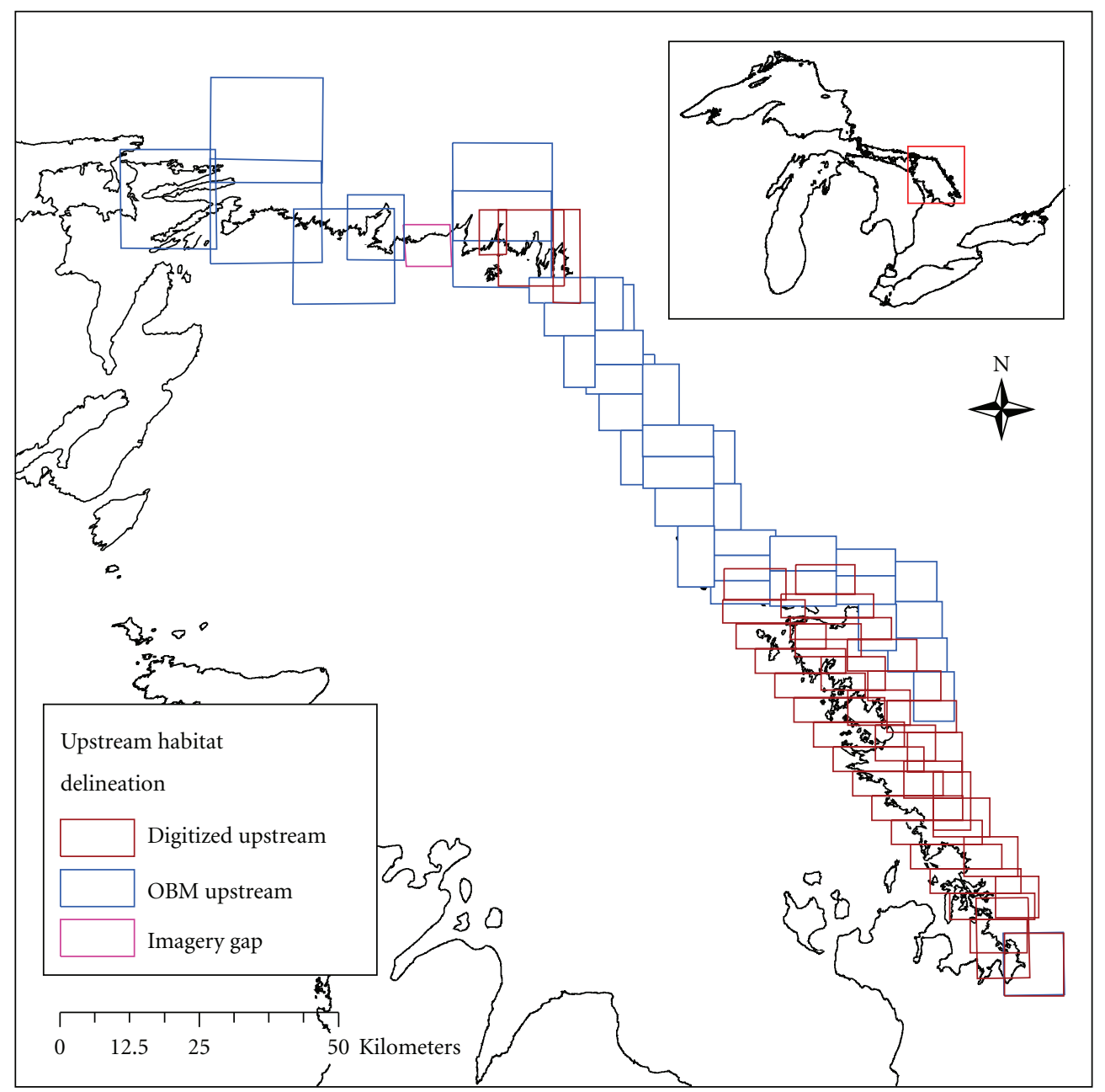

FIGURE 3: Map showing the boundaries of imagery that was used to digitize upstream habitat (indicated in red). For all other areas, upstream habitat was obtained from corresponding Ontario Base Maps (obtained from OMNR; indicated in blue).

(iii) Upstream wetland (UP) habitat corresponded to all remaining wetlands that were hydrologically connected to the bay via surface water and that occur within a $2 \mathrm{~km}$ buffer of the shoreline. In vast majority of cases, beaver activity created conditions that separated the upper limit of the HM from the lower limit of the UP wetland habitat. Since these beaver ponds can be seasonally connected with downstream habitat, they can act as potential fish habitat for fish communities in the affected coastal wetlands and were therefore included in the inventory. Due to the large number of UP along the eastern and northern shore of Georgian Bay, there was not enough time to delineate UP habitat in all 81 images. UP was delineated for 21 IKONOS images covering the region from Parry Sound south to Severn Sound (Figure 3). These delineations were compared to existing wetland delineations in the OMNRs [28] Ontario Base Map (OBM) that corresponds to our UP habitat. We found the OBM wetland delineations provided comparable coverage (data not shown) and therefore the OBM wetland layer was directly incorporated into the MCWI for the remaining areas (60 images). We should note, however, that some of the wetlands incorporated into the MCWI from the OBM survey may not be directly connected by surface water and the extent of this error has not yet been determined.

To standardize variations among technicians working on this project, all technicians were first trained on the same five images. Only when they achieved an acceptable level of precision (greater than $85 \%$ similarity) were they allowed to contribute to the project. To further reduce technician bias associated with discerning the lower extent of LM, only one technician was assigned to digitize this habitat category for majority of the satellite images. There was less subjectivity associated with delineations of HM and UP, and, hence, more than one technician was assigned to these habitats. Once all polygons were digitized, a single technician went through the entire data set to ensure that edges between habitat categories did not overlap and that no wetlands had been missed. 
TABLE 1: List of OMNR watershed codes and the assigned name to reflect the major tributary or geographic feature. Watershed area, the total number of marshes, and the amount of marsh area within each watershed are provided.

\begin{tabular}{|c|c|c|c|c|c|}
\hline $\begin{array}{l}\text { Quaternary } \\
\text { watershed ID }\end{array}$ & Watershed name & $\begin{array}{l}\text { Watershed area } \\
\text { (ha) }\end{array}$ & Wetland number & $\begin{array}{l}\text { Total marsh habitat } \\
\text { (ha) }\end{array}$ & $\begin{array}{l}\text { Number of marshes } \\
>2 \text { ha }\end{array}$ \\
\hline 2CE-01 & La Cloche & 27269 & 82 & 132.4 & 15 \\
\hline 2CE-11 & La Cloche Islands & 2542 & 34 & 12.6 & 0 \\
\hline 2CF-02 & Philip Edward Island & 4909 & 367 & 433.2 & 56 \\
\hline 2CF-18 & MacGregor-Sampson Islands & 2179 & 266 & 350.7 & 32 \\
\hline 2CG-06 & Great La Cloche Island & 9643 & 136 & 394.2 & 35 \\
\hline 2CG-32 & Bedford-Rous Islands & 1937 & 29 & 7.9 & 0 \\
\hline 2CG-33 & Strawberry-Heywood Islands & 1595 & 12 & 72.8 & 8 \\
\hline $2 \mathrm{CH}-01$ & Beaverstone River & 12957 & 196 & 500.1 & 39 \\
\hline $2 \mathrm{CH}-03$ & Killarney & 62878 & 594 & 915.5 & 87 \\
\hline $2 \mathrm{CH}-04$ & Whitefish River & 26640 & 1162 & 841.1 & 78 \\
\hline $2 \mathrm{CH}-17$ & Killarney Islands & 2640 & 524 & 233.7 & 15 \\
\hline 2DD-01 & French River & 126103 & 1225 & 792.8 & 91 \\
\hline 2DD-03 & Pickerel River & 105176 & 660 & 385.0 & 41 \\
\hline 2DD-26 & Outer French-Pickerel Islands & 3484 & 749 & 257.7 & 16 \\
\hline 2EA-01 & Henvey Inlet-Key River & 19669 & 392 & 751.3 & 90 \\
\hline 2EA-03 & Sandy Bay & 6057 & 118 & 280.2 & 23 \\
\hline 2EA-04 & Giroux River & 10949 & 225 & 285.9 & 37 \\
\hline 2EA-05 & Pointe au Baril & 11554 & 566 & 939.6 & 116 \\
\hline 2EA-06 & Shebeshekong River & 19720 & 275 & 880.7 & 83 \\
\hline 2EA-07 & Parry Island & 7666 & 249 & 586.4 & 40 \\
\hline 2EA-08 & Spider Lake & 8816 & 280 & 297.9 & 36 \\
\hline 2EA-09 & Still River & 23649 & 14 & 38.2 & 3 \\
\hline 2EA-10 & Magnetawan-Naiscoot Rivers & 92622 & 235 & 448.5 & 49 \\
\hline 2EA-11 & Naiscoot Lake & 21331 & 9 & 5.5 & 0 \\
\hline 2EA-13 & Shawanaga River & 30979 & 201 & 329.5 & 48 \\
\hline 2EA-14 & Parry Sound & 59479 & 241 & 434.2 & 55 \\
\hline 2EA-15 & Seguin River & 8330 & 27 & 41.2 & 7 \\
\hline 2EA-24 & Eastern Coast Islands & 11854 & 1835 & 1386.8 & 102 \\
\hline 2EB-01 & Moon-Musquash Islands & 4392 & 1088 & 572.0 & 39 \\
\hline 2EB-02 & Moon-Musquash Rivers & 71731 & 916 & 2394.0 & 179 \\
\hline 2EB-03 & Muskoka Lakes & 18578 & 6 & 7.4 & 1 \\
\hline $2 \mathrm{EC}-17$ & Severn River & 70445 & 423 & 973.7 & 77 \\
\hline 2EC-18 & Beausoleil-Severn Islands & 2913 & 798 & 746.4 & 52 \\
\hline 2ED-04 & Sturgeon River & 18887 & 19 & 135.2 & 7 \\
\hline 2ED-05 & Coldwater River & 21727 & 149 & 1131.0 & 29 \\
\hline 2ED-06 & North River & 32214 & 31 & 97.3 & 4 \\
\hline 2ED-17 & Giants Tomb Island* & 564 & 0 & 0.0 & 0 \\
\hline
\end{tabular}

*Currently no satellite image coverage for the watershed in the MCWI.

We assigned wetlands to the quaternary watersheds (acquired as OBM from [28]; Figure 4) that surrounded them using a spatial join tool in ArcMap 9.2 (ESRI Inc., Redlands, CA, USA, 2006). When a wetland occurred on the boundaries of two or more watersheds, it was assigned to the watershed that held the majority of the wetland. If it was unclear to which particular watershed a wetland should be assigned, the wetland was assigned to both. This is the reason why there is a slight discrepancy (occurred in $<5 \%$ of the wetlands) between total area when all wetlands are summed without regard to watershed origin and when they are pooled after they have been sorted by quaternary watershed.

2.4. Comparison of Differences in Inventories. The shapefile for the GLCWCI was available online from the Great Lakes Commission's website [29] and was used to conduct a comparison of the MCWI and GLCWCI. The wetland layers 
TABLE 2: Comparison of the total area of low-marsh, high-marsh, and upstream wetlands for eastern and northern Georgian Bay identified in the GLCWC and the MCWI.

\begin{tabular}{|c|c|c|c|c|c|c|}
\hline & $\begin{array}{c}\text { GLCWC area } \\
\text { (ha) }\end{array}$ & $\begin{array}{c}\text { GLCWC polygon } \\
\text { number }\end{array}$ & $\begin{array}{l}\text { GLCWC mean size } \\
\text { (ha) }\end{array}$ & MCWI area (ha) & $\begin{array}{l}\text { MCWI polygon } \\
\text { number }\end{array}$ & $\begin{array}{c}\text { MCWI mean size } \\
\text { (ha) }\end{array}$ \\
\hline Total low marsh & 297.8 & 170 & 1.8 & 5376.1 & 3771 & 1.4 \\
\hline Total low marsh $>2$ ha & 297.8 & 170 & 1.8 & 4043.9 & 414 & 9.8 \\
\hline Total high marsh & 586.7 & 234 & 2.5 & 3297.5 & 6255 & 0.5 \\
\hline Total high marsh $>2$ ha & 586.7 & 234 & 2.5 & 1842.1 & 289 & 6.4 \\
\hline Total upstream & 1762.4 & 379 & 4.7 & 8676.1 & 2603 & 3.3 \\
\hline Total upstream $>2$ ha & 1762.4 & 379 & 4.7 & 7381.2 & 883 & 8.4 \\
\hline Total wetland & 3660.8 & 696 & 5.3 & 17349.7 & 12629 & 1.4 \\
\hline Total wetland $>2$ ha & 3660.8 & 696 & 5.3 & 13267.1 & 1586 & 8.4 \\
\hline
\end{tabular}

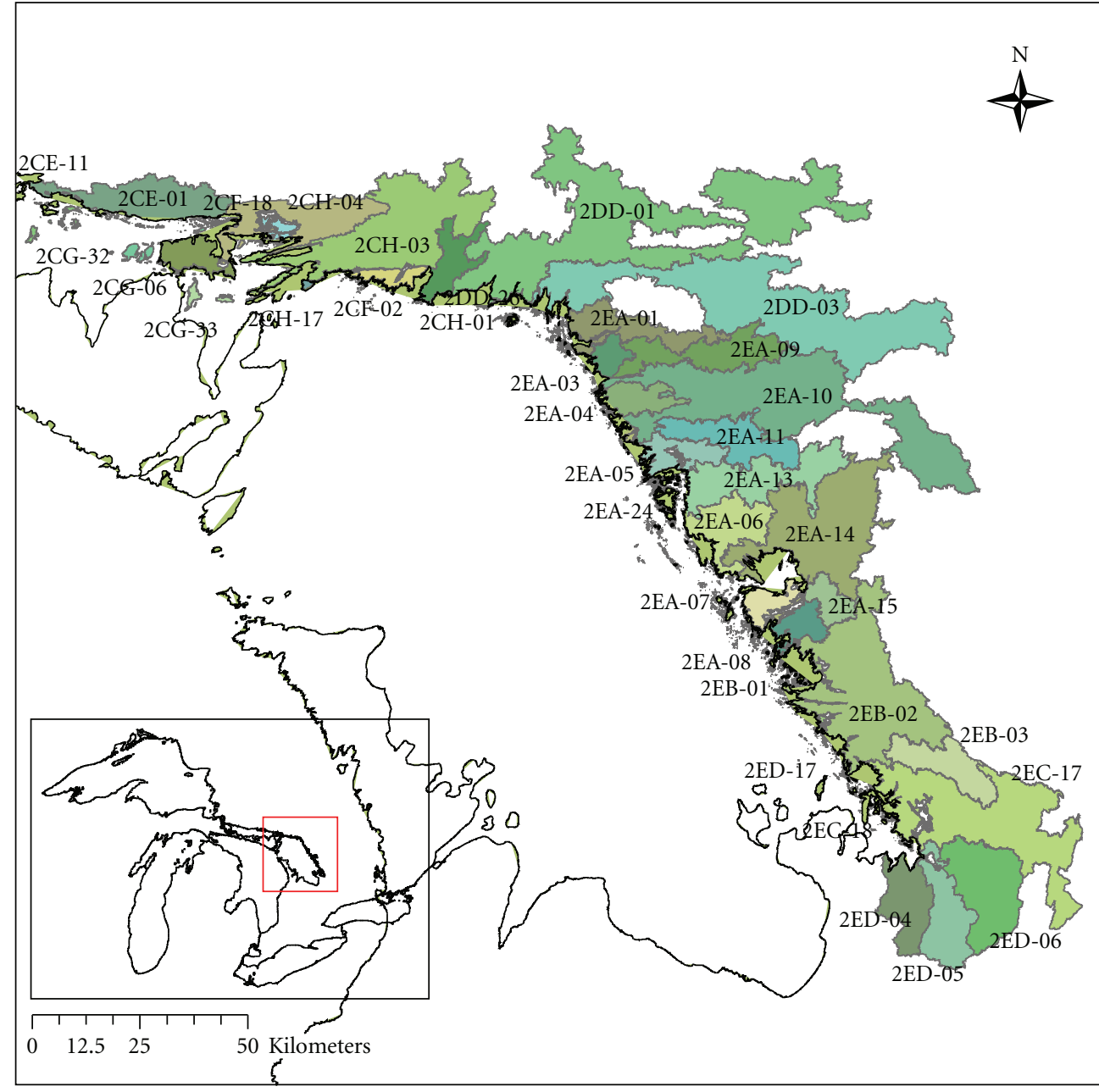

FIgURE 4: Quaternary watershed location for eastern and northern Georgian Bay, obtained from OMNR. See Table 1 for list of names corresponding to each OMNR code. The shading of the watersheds is for illustrative purposes only.

created in the MCWI were used to clip out portions of the GLCWCI corresponding to the Coastal and Upstream regions. Our "Coastal" zone is the same as the "Lacustrine" class defined by the GLCWCI and can be used interchangeably. We note, however, that there is no category that matches our "Upstream" portion, but in the GLCWCI shapefile, there are regions that would be defined as "Upstream," even though they were not actually classified as such. To assess differences between inventories, we used a GIS to calculate total area of wetlands for the respective inventories. The comparison included wetlands in the MCWI and the GLCWCI along the northern and eastern shore of Georgian 
TABLE 3: Number and areal coverage of low-marsh, high-marsh, and upstream wetlands for each of the 37 quaternary watersheds along eastern and northern Georgian Bay (see location of each in Figure 5).

\begin{tabular}{|c|c|c|c|c|c|c|}
\hline Watershed name & $\begin{array}{c}\text { Number of } \\
\text { low-marsh units }\end{array}$ & $\begin{array}{l}\text { Area of low } \\
\text { marsh (ha) }\end{array}$ & $\begin{array}{c}\text { Number of } \\
\text { high-marsh units }\end{array}$ & $\begin{array}{l}\text { Area of high } \\
\text { marsh (ha) }\end{array}$ & $\begin{array}{c}\text { Number of } \\
\text { upstream wetlands }\end{array}$ & $\begin{array}{c}\text { Area of upstream } \\
\text { wetlands (ha) }\end{array}$ \\
\hline Beausoleil-Severn Islands & 303 & 484.7 & 492 & 254.2 & 3 & 7.5 \\
\hline Beaverstone River & 44 & 139.6 & 103 & 116.7 & 50 & 247.4 \\
\hline Bedford-Rous Islands & 14 & 5.6 & 15 & 2.4 & 0 & 0.0 \\
\hline Coldwater River & 49 & 796.7 & 100 & 334.4 & 0 & 0.0 \\
\hline Eastern Coast Islands & 629 & 631.5 & 1035 & 403.5 & 169 & 353.1 \\
\hline French River* & 413 & 164.4 & 554 & 175.1 & 260 & 462.7 \\
\hline Giants Tomb* & 0 & 0.0 & 0 & 0.0 & 0 & 0.0 \\
\hline Giroux River & 66 & 77.4 & 92 & 97.9 & 70 & 121.2 \\
\hline Great La Cloche Island & 14 & 25.5 & 16 & 2.9 & 106 & 365.8 \\
\hline Henvey Inlet-Key River & 77 & 108.2 & 134 & 95.5 & 183 & 594.8 \\
\hline Killarney & 194 & 314.0 & 239 & 174.3 & 162 & 430.1 \\
\hline Killarney Islands & 280 & 143.4 & 224 & 56.5 & 20 & 33.8 \\
\hline La Cloche & 25 & 63.2 & 34 & 25.0 & 23 & 44.2 \\
\hline La Cloche Islands & 10 & 3.0 & 24 & 9.7 & 0 & 0.0 \\
\hline MacGregor-Sampson Islands & 81 & 72.4 & 162 & 91.9 & 23 & 186.4 \\
\hline Magnetawan-Naiscoot Rivers & 27 & 60.8 & 49 & 83.5 & 167 & 347.7 \\
\hline Moon-Musquash Islands & 426 & 293.3 & 620 & 135.9 & 42 & 161.9 \\
\hline Moon-Musquash Rivers & 271 & 420.6 & 487 & 268.1 & 159 & 1707.6 \\
\hline Muskoka Lakes & 0 & 0.0 & 0 & 0.0 & 6 & 7.4 \\
\hline Naiscoot Lake & 0 & 0.0 & 0 & 0.0 & 9 & 5.5 \\
\hline North River & 6 & 0.9 & 25 & 96.4 & 0 & 0.0 \\
\hline $\begin{array}{l}\text { Outer French-Pickerel } \\
\text { Islands* }\end{array}$ & 359 & 125.4 & 343 & 80.0 & 46 & 51.8 \\
\hline Parry Island & 83 & 108.1 & 126 & 67.7 & 40 & 410.7 \\
\hline Parry Sound & 64 & 104.9 & 70 & 97.6 & 114 & 275.8 \\
\hline Philip Edward Island & 125 & 169.7 & 150 & 65.4 & 92 & 198.0 \\
\hline Pickerel River & 235 & 132.7 & 257 & 80.7 & 170 & 180.4 \\
\hline Pointe au Baril & 105 & 126.3 & 193 & 109.2 & 270 & 708.5 \\
\hline Sandy Bay & 29 & 41.8 & 52 & 20.8 & 39 & 254.0 \\
\hline Seguin River & 1 & 4.4 & 9 & 2.6 & 17 & 34.2 \\
\hline Severn River & 131 & 447.3 & 249 & 223.4 & 43 & 303.0 \\
\hline Shawanaga River & 39 & 60.5 & 57 & 29.3 & 109 & 271.1 \\
\hline Shebeshekong River & 42 & 200.5 & 96 & 95.1 & 137 & 585.0 \\
\hline Spider Lake & 78 & 75.7 & 162 & 45.1 & 40 & 177.1 \\
\hline Still River & 7 & 0.8 & 2 & 0.3 & 5 & 37.1 \\
\hline Strawberry-Heywood Islands & 1 & 0.1 & 1 & 0.0 & 10 & 72.7 \\
\hline Sturgeon River & 6 & 100.6 & 13 & 34.6 & 0 & 0.0 \\
\hline Whitefish River & 410 & 256.9 & 677 & 231.5 & 75 & 352.8 \\
\hline
\end{tabular}

*Indicates incomplete wetland identification due to incomplete imagery coverage within the coastal zone.

Bay. We excluded all wetlands $<2$ ha in the MCWI to make this criterion consistent with that of the GLCWCI.

\section{Results}

3.1. McMaster Coastal Wetland Inventory. In total, 73 IKONOS and 8 QuickBird images were digitized, and each image was delineated separately for both the high-marsh and low-marsh habitats. For upstream wetland habitat, however, only 21 IKONOS images were delineated (south of Parry Sound) with the remaining data being filled in from the OBM wetland layer (Figure 3).

Despite our best efforts, we were unable to acquire appropriate imagery to fill one small gap in northern Georgian Bay (Figure 2). We know that wetlands exist in 


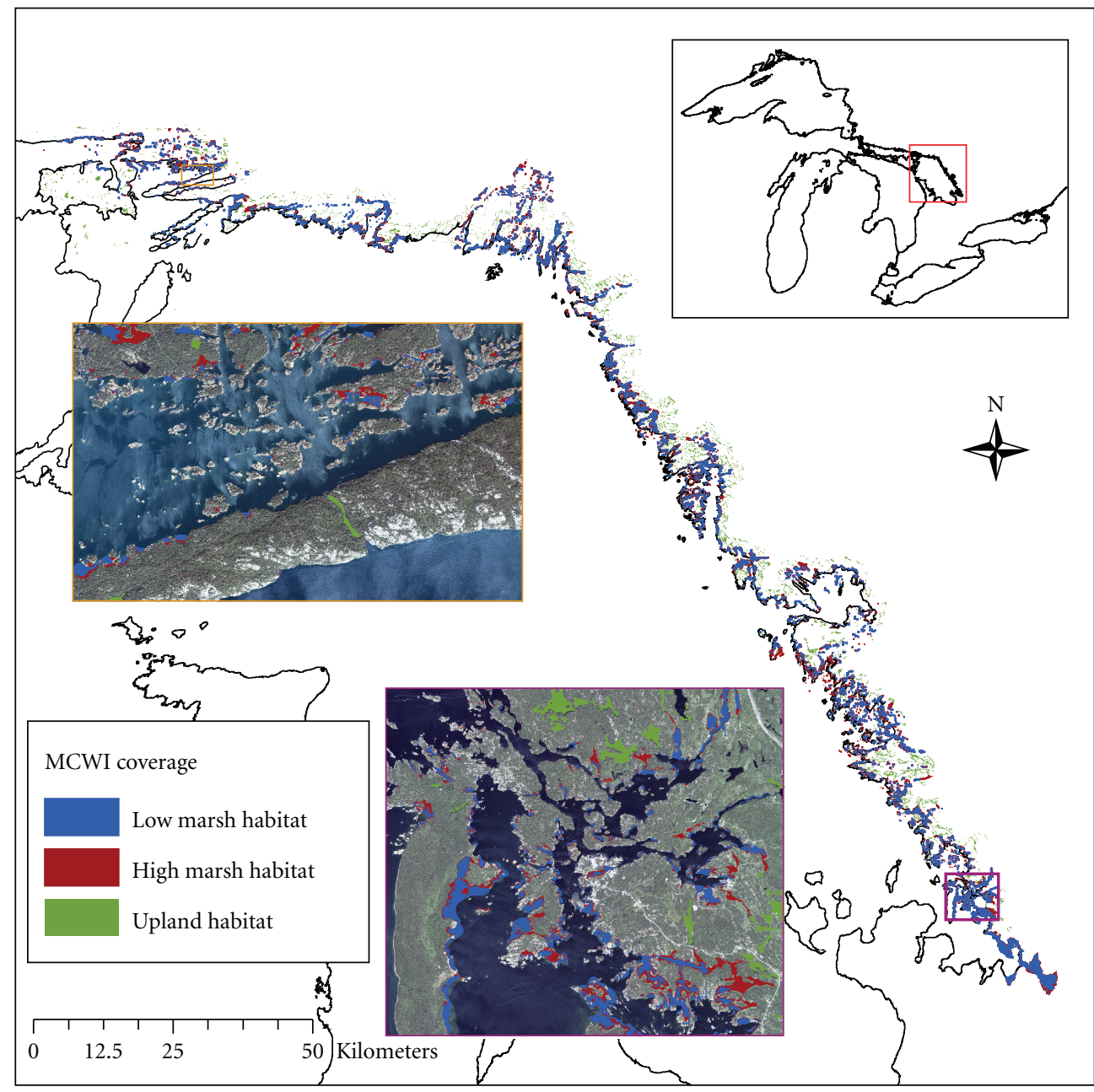

FIgURE 5: Overview map of the McMaster Coastal Wetland Inventory, covering eastern and northern Georgian Bay within $2 \mathrm{~km}$ of the shoreline. The two insets provide a closeup of the region near MacGregor Bay (top; orange) and the Honey Harbour (bottom; purple).

these gaps because we have conducted field sampling there (Chow-Fraser, unpub. data). Therefore, the estimate in this document should be considered a slight underestimate of the actual amount of coastal wetland habitat in northern Georgian Bay, and future efforts should be made to fill this gap with some other satellite media of the same vintage. Relative to the remainder of the shoreline in eastern and northern Georgian Bay, this gap in imagery amounts to only a small fraction of the shoreline and should be relatively easy to update as soon as appropriate imagery has been acquired.

In total, 3771 units (414 units $>2$ ha) of low marsh, 6355 units ( 289 units $>2$ ha) of high marsh, and 2603 units (883 units $>2$ ha) of upland wetland are included in the MCWI. Size of wetlands in LM habitat varied a great deal, with a mean of $1.4( \pm 12.0)$ ha and a median of 0.3 ha. By comparison, those in HM habitat were more uniform in size, with a mean of $0.5( \pm 2.2)$ ha and median of 0.1 ha, and those in the UP habitat were larger, with a mean of 3.3 $( \pm 9.0)$ ha and a median of 1.1 ha. UP habitat covered the largest area ( $8676 \mathrm{ha}$ ), followed by LM (5376 ha) and HM (3298 ha) (Table 2; Figure 4).

Along the eastern and northern shores of Georgian Bay, there are a total of 37 quaternary watersheds ranging in size from 564 ha (Giants Tomb) to 126103 ha (French River) (Figure 5; Table 1). The largest amount of wetland habitat (2394 ha) was found in the Moon-Musquash watershed (Table 1). When sorted by different type of habitat, however, we found that the Coldwater watershed was associated with the greatest amount of LM habitat (49 units with a total area of 797 ha) (Table 3). It was surprising that this LM habitat only accounted for $3.7 \%$ of the total Coldwater watershed area, when the LM habitat in Beausoleil-Severn Island accounted for $25.6 \%$ of the total watershed area; Islands in Beausoleil-Severn were also associated with the highest percentage of HM habitat (8.7\%). The Eastern Coast Islands watershed contained 1035 units of HM, for a total area of 404 ha (Table 3). The Moon-Musquash River watershed contained the greatest amount of UP habitat, with 159 units 


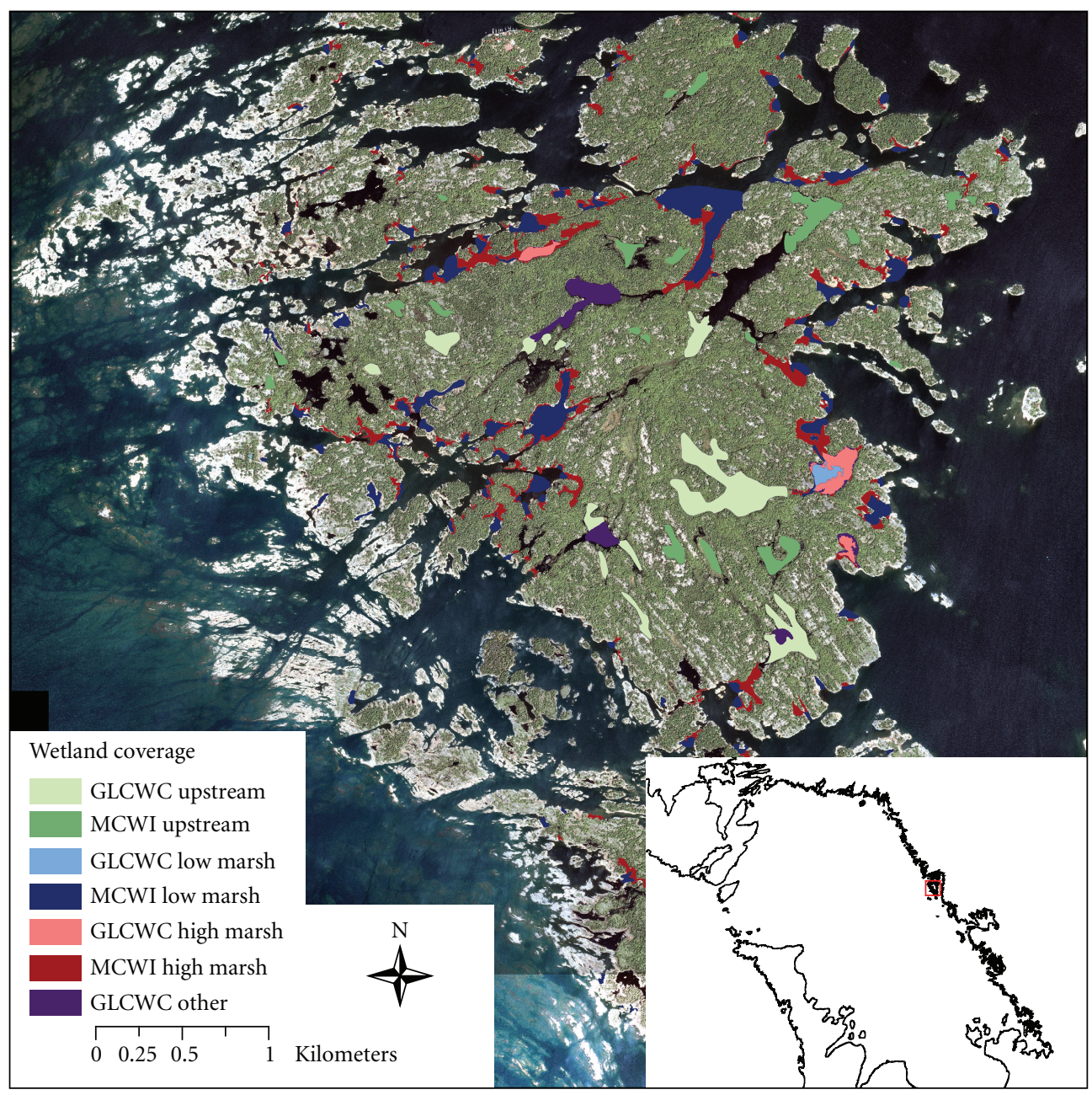

FIGURE 6: Comparison of coverage between McMaster Coastal Wetland Inventory (MCWI) and Great Lake Coastal Wetland Consortium (GLCWC) inventory in the Honey Harbour region. Areas identified as upstream, low marsh, and high marsh in the GLCWC are also in the MCWI; however, areas identified as upstream, low marsh, and high marsh in the MCWI do not occur in the GLCWC. Areas in purple represent habitat that was included in the GLCWC but not in the MCWI.

and a total area of 1708 ha (Table 3), while the MacGregorSampson Islands watershed had the highest percentage of UP habitat $(8.6 \%)$ of all 37 quaternary watersheds.

3.2. MCWI/GLCWCI Comparison. We compared the total amount of wetlands in both the MCWI and the GLCWCI with respect to wetlands $>2$ ha (Table 2). There were 1586 wetland units in the MCWI, covering an area of 13267 ha; by comparison, the GLCWCI only included 696 wetland units, covering a total area of 3660 . Within the Coastal zone, the MCWI included more than twice as many LM (414 versus 170 ) and UP (883 versus 379 ) units and a greater number of HM units (289 versus 234). In terms of area, however, there was almost 14 times the area of LM (4044 versus $298 \mathrm{ha}$ ), greater than three times the amount of HM (1842 versus 587), and more than six times the amount of UP (7381 versus 1762 ha) habitat. The greater number of wetland units and area included in the MCWI is despite the inclusion of
1014 ha of wetland area that was unique to the GLCWCI (see Figure 6).

\section{Discussion}

The McMaster Coastal Wetland Inventory is currently the most comprehensive inventory of coastal wetlands for eastern and northern Georgian Bay. With the completion of this inventory, we can now update the total coastal wetland habitat area for the Canadian side of the Great Lakes. With the inclusion of the nonoverlapping areas of the MCWI, the Great Lakes contain 78405 ha of coastal wetland habitat in Canada, increasing the total for Lake Huron by $47.6 \%$ to $30882 \mathrm{ha}$. We have identified all coastal marshes in a region where complete data has been lacking and that have filled an important void in the distribution of coastal wetland habitat in the Great Lakes basin. This is an important advancement 
in the tools available for wetland managers where basinwide decision making is essential for the future persistence of these habitats. By accessing a large collection of satellite imagery, we have been able to fill in major gaps in the Great Lakes Coastal Wetland Consortium Inventory along eastern and northern Georgian Bay that had been noted by the authors [10]. Coastal wetlands are dynamic systems that vary in wetland size and dominant vegetation type when water levels fluctuate seasonally and annually [21, 30, 31]. In order to create an inventory that provides consistent wetland coverage, it is essential that all delineations utilize imagery acquired during similar water-level conditions. If there is any temporal discrepancy in image acquisition, wetlands in images that were acquired during low water levels may have more HM habitat [31] than the same wetlands delineated using imagery acquired during higher water levels. All wetlands in the MCWI were digitized from high-resolution IKONOS and QuickBird satellite imagery acquired during a period of low water levels between 2002 and 2008 (mean of $176.12 \mathrm{~m} \pm 0.13$ ). This means that all wetland areas in our inventory are standardized and are directly comparable. Conversely, wetlands in the GLCWCI were digitized from aerial photos or satellite images acquired at different years (from 1983 to 1999; mean of $176.78 \pm$ 0.29 ) and were not standardized to a consistent water level. Although wetlands digitized in the GLCWCI may provide information on wetland location and some UP boundaries, regional comparisons of LM and HM wetland area may not be possible due to the potential influence of interannual water level variation and resulting vegetation changes.

The MCWI and the GLCWCI also differ with respect to the level of detail provided by each inventory for eastern and northern Georgian Bay. The GLCWCI only identified 21\% of wetlands (by area) available in the MCWI. The MCWI raises some important issues concerning the minimum mapping unit of inventories. The GLCWCI used a minimum mapping unit of 2 ha to identify coastal wetland habitat. In our objectives for the MCWI, we decided to identify all coastal marsh habitat possible with the resolution of our imagery. This proved to identify a unique characteristic of this region in that a majority of the coastal wetlands are $<2$ ha. A minimum mapping unit of $<2$ ha would exclude a large portion of the data in this project which was meant to identify critical fish habitat. Accordingly, we suggest that the GLCWCI should not be used to estimate the amount of coastal fish habitat in Georgian Bay because the amount of LM habitat in the MCWI was 13 times higher for wetlands $>2$ ha and 18 times higher for all wetlands regardless of size. As outlined previously, the major differences between inventories reflect how they were created. Authors of the GLCWCI indicated that they relied heavily on OWESidentified wetlands (minimum size of $2 \mathrm{ha}$ ) and availability of aerial photography to fill the considerable gaps in eastern and northern Georgian Bay. Unfortunately, there were more data available for upstream wetlands than for those in the coastal zone because the initial acquisitions of aerial photographs were for forest survey purposes. As a result, the authors also recognized that there were major gaps in coverage for the GLCWCI and that the missed areas likely contained a considerable number of coastal wetlands [10]. In this respect, the MCWI should have the most complete coverage given that the satellite images we acquired provided a seamless coverage of the entire $2 \mathrm{~km}$ coastline of eastern and most of northern Georgian Bay.

Herdendorf [4] identified approximately 1500 wetlands in the Great Lakes (total area of $1730 \mathrm{~km}^{2}$ ) that were sufficiently large to have local ecological importance. Among these, only one, Matchedash Bay, was found in eastern Georgian Bay. We feel that this is a severe underrepresentation of large wetlands of ecological importance in Georgian Bay and that Herdendorf's list should be updated with information from this study. We speculate that size alone is not a sufficient criterion for determining ecological significance. The Ontario Wetland Evaluation System [12] indicates that small coastal wetlands (i.e., $<2$ ha) can be grouped together to form complexes if there is a biological or hydrological rationale for doing so. For Georgian Bay, many of the smaller wetlands could be grouped into complexes since they are often found close together (within $750 \mathrm{~m}$ ). With completion of the MCWI, we are now in the position to create the complexes, once we have a better understanding of the role that small wetlands play in terms of ecosystem functions, such as providing suitable nursery and spawning habitat for the Lake Huron fishery.

Water levels in the Great Lakes, specifically in Lake Michigan-Huron, are expected to decline as a result of climate change $[19,20]$. These changes will alter the distribution, areal coverage, and vegetation structure in the coastal wetlands of eastern Georgian Bay. Wetland habitat in the MCWI has been classified according to three unique habitat zones: low marsh, which is critical habitat for fish [6], high marsh which is critical habitat for marsh birds and turtles [7, 32], and upstream habitat, that plays a critical role in controlling water quality in downstream habitats (UP) [33]. Both Wei and Chow-Fraser [34] and Midwood and Chow-Fraser [35] utilized IKONOS satellite imagery to map different types of fish habitat in the LM portion of coastal wetlands. In the HM zone, Rokitnicki-Wojcik et al. [36] developed a method that can provide detailed maps for HM vegetation. These methods can now be applied to map all LM and HM habitat in the MCWI that was delineated with IKONOS imagery. This mapping should produce consistent, baseline maps of fish habitat as well as meadow habitat for majority of coastal wetlands in eastern and northern Georgian Bay. With the acquisition of new satellite imagery, changes in vegetation coverage can be monitored and linked to the observed changes in water level in Lake MichiganHuron.

DeCatanzaro et al. [16] were able to use road density as a surrogate for human development. They found poorer water quality (i.e., increased nutrients, conductivity, and suspended solids) in coastal wetlands adjacent to quaternary watersheds that were associated with high road density. Majority of coastal wetlands in Georgian Bay occur within watersheds that have low road density except for two (Sturgeon River and Coldwater River) [16]. The highest density occurs in the Coldwater River watershed $(16.1 \mathrm{~m} / \mathrm{ha})$, and this watershed also contains the largest single area of 
LM habitat, and this may mean that one of the largest fish spawning areas in Georgian Bay is currently threatened by human development. Eleven of the 32 watersheds that are not currently being impacted by human development have large chains of islands. These island watersheds represent ideal conservation sites since they have limited human access, except for some cottage development. In addition, despite the fact that these islands cover less than $5 \%$ of the total watershed area within the basin, they account for nearly a quarter of all coastal habitats in eastern and northern Georgian Bay. A first step towards conserving critical wetland habitat in Georgian Bay should be to protect these islands, and, currently, the Georgian Bay Land Trust (GBLT) has managed to acquire and protect islands covering over 250 ha (http://www.GBLT.org/).

In creating the MCWI, we have provided a consistent and accurate inventory of coastal wetlands in eastern and northern Georgian Bay under low water level conditions. This project took three years to complete with help of many GIS technicians. At all times, we tried to ensure that each technician was delineating at a consistent level of accuracy. We do acknowledge that small differences in the date of image acquisition, which created slight differences in ground feature colour, may result in some discrepancy in wetland delineation. This type of error in image interpretation is unavoidable, and we believe the resulting error does not significantly alter the accuracy of the MCWI. The incorporation of the OBM wetland layer into the MCWI was necessary in order to complete the project in a timely fashion. While we found that this layer provided a sufficient level of coverage for the UP portion of our inventory, manual delineation designed specifically to identify upland habitat which was connected via surface water may provide a more accurate inventory.

While we believe that the MCWI in its current form provides a useful and comprehensive tool that should be adopted and utilized by conservation managers, we know that it can be improved with further enrichment. First, the image gap in a small portion of the French River Delta needs to be filled and all wetlands in this area need to be delineated. Secondly, wetlands identified by the inventory need to be grouped into ecologically relevant complexes in accordance with the complexing rules outlined in the OWES [12] or with suitable modifications. Finally, we recommend that satellite imagery be acquired every five years for a statistically valid subset of the MCWI. This will allow researchers and managers to track general trends in areal wetland coverage change as water levels fluctuate.

Here, we show how to create a complex habitat-based inventory of coastal wetlands for a large expanse of eastern and northern Georgian Bay, Ontario, Canada. The application of this project beyond the scope of the Laurentian Great Lakes is widespread as managers are continually in need of cost-effective methods to produce high-quality and ecologically relevant geospatial data. Although aerial photography is considered the gold standard for habitat identification, in the context of the Great Lakes, the MCWI is able to provide a static view of habitat conditions across a significant portion of the entire basin, which has proven to be too costly in past projects (GLCWCI). We recommend that managers undertaking mapping projects at similar spatial scales as the MCWI and GLCWCI consider the benefits of having contiguous data coverage within a time scale where geographic comparisons are valid and regional differences due to succession are minimized.

\section{Acknowledgments}

The authors thank Georgian Bay Forever for providing a research grant to $\mathrm{P}$. Chow-Fraser to undertake this three-year project and for giving them access to the IKONOS imagery. Many GIS technicians contributed to the final inventory, but Kristina Cimaroli undoubtedly made the most important contributions. They acknowledge additional funding in the form of an NSERC scholarship to D. Rokitnicki and an OGS scholarship to J. Midwood.

\section{References}

[1] P. A. Keddy, L. H. Fraser, A. I. Solomeshch et al., "Wet and wonderful: the world's largest wetlands are conservation priorities," BioScience, vol. 59, no. 1, pp. 39-51, 2009.

[2] J. Li and W. Chen, "A rule-based method for mapping Canada's wetlands using optical, radar and DEM data," International Journal of Remote Sensing, vol. 26, no. 22, pp. 5051-5069, 2005.

[3] K. Jones, Y. Lanthier, P. van der Voet, E. van Valkengoed, D. Taylor, and D. Fernández-Prieto, "Monitoring and assessment of wetlands using Earth Observation: the GlobWetland project," Journal of Environmental Management, vol. 90, no. 7, pp. 2154-2169, 2009.

[4] C. E. Herdendorf, "Morphometric factors in the formation of Great Lakes coastal wetlands," Aquatic Ecosystem Health and Management, vol. 7, no. 2, pp. 179-197, 2004.

[5] P. Chow-Fraser and D. Albert, "Identification of eco-reaches of Great Lakes Coastal Wetlands that have high biodiversity values," Discussion Paper for SOLEC '98, Environment CanadaUSEPA Publication, 1999.

[6] A. Wei, P. Chow-Fraser, and D. Albert, "Influence of shoreline features on fish distribution in the Laurentian Great Lakes," Canadian Journal of Fisheries and Aquatic Sciences, vol. 61, no. 7, pp. 1113-1123, 2004.

[7] L. A. Smith and P. Chow-Fraser, "Implications of the speciesarea relationship on sampling effort for marsh birds in southern ontario," Wetlands, vol. 30, no. 3, pp. 553-563, 2010.

[8] E. A. Snell, "Wetland distribution and conversion in southern ontario: Canada Land Use Monitoring Program," Working Paper no. 48, Inland Waters and Lands Directorate, Environment Canada, 1987.

[9] M. Cvetkovic and P. Chow-Fraser, "Use of ecological indicators to assess the quality of Great Lakes coastal wetlands," Ecological Indicators, vol. 11, no. 6, pp. 1609-1622, 2011.

[10] J. Ingram, K. Holmes, G. Grabas et al., "Development of a coastal wetland database for the Great Lakes Canadian Shoreline," Final Report, The Great Lakes Commission, 2004.

[11] Environment Canada and Ontario Ministry of Natural Resources, The Ontario Great Lakes Coastal Wetland Atlas: A Summary of Information (1983-1997), 2003.

[12] OMNR, Ontario Wetland Evaluation System. Northern Manual, Ontario Ministry of Natural Resources (OMNR), No.50254, 1993. 
[13] P. Chow-Fraser, "Development of the wetland water quality index for assessing the quality of Great Lakes coastal wetlands," in Coastal Wetlands of the Laurentian Great Lakes: Health, Habitat, and Indicators, T. P. Simon and P. M. Stewart, Eds., pp. 137-166, Indiana Biological Survey, Bloomington, Ind, USA, 2006.

[14] M. V. Croft and P. Chow-Fraser, "Use and development of the wetland macrophyte index to detect water quality impairment in fish habitat of Great Lakes coastal marshes," Journal of Great Lakes Research, vol. 33, no. 3, pp. 172-197, 2007.

[15] T. S. Seilheimer and P. Chow-Fraser, "Application of the wetland fish index to Northern Great Lakes marshes with emphasis on Georgian Bay coastal wetlands," Journal of Great Lakes Research, vol. 33, no. 3, pp. 154-171, 2007.

[16] R. DeCatanzaro, M. Cvetkovic, and P. Chow-Fraser, "The relative importance of road density and physical watershed features in determining coastal marsh water quality in georgian bay," Environmental Management, vol. 44, no. 3, pp. 456467, 2009.

[17] M. V. Croft and P. Chow-Fraser, "Non-random sampling and its role in habitat conservation: a comparison of three Wetland macrophyte sampling protocols," Biodiversity and Conservation, vol. 8, no. 9, pp. 2283-2306, 2009.

[18] EPA (Environmental Protection Agency), "Biocriteria-aquatic life use support,” 2007, http://www.epa.gov/waterscience/ biocriteria/alus/ref2.html

[19] L. D. Mortsch and F. H. Quinn, "Climate change scenarios for Great Lakes Basin ecosystem studies," Limnology and Oceanography, vol. 41, no. 5, pp. 903-911, 1996.

[20] C. E. Sellinger, C. A. Stow, E. C. Lamon, and S. S. Qian, "Recent water level declines in the Lake Michigan-Huron system," Environmental Science and Technology, vol. 42, no. 2, pp. 367373, 2008.

[21] P. A. Keddy and A. A. Reznicek, "Great Lakes vegetation dynamics: the role of fluctuating water levels and buried seeds," Journal of Great Lakes Research, vol. 12, no. 1, pp. 2536, 1986.

[22] C. Quinlan and G. Mulamoottil, "The effects of water level fluctuations on three Lake Ontario shoreline marshes," Canadian Water Resource Journal, vol. 12, pp. 64-77, 1987.

[23] D. J. Jude and J. Pappas, "Fish utilization of Great Lakes coastal wetlands," Journal of Great Lakes Research, vol. 18, no. 4, pp. 651-672, 1992.

[24] R. G. Randall, C. K. Minns, V. W. Cairns, and J. E. Moore, "The relationship between an index of fish production and submerged macrophytes and other habitat features at three littoral areas in the Great Lakes," Canadian Journal of Fisheries and Aquatic Sciences, vol. 53, supplement 1, pp. 35-44, 1996.

[25] L. Wang, W. P. Sousa, P. Gong, and G. S. Biging, "Comparison of IKONOS and QuickBird images for mapping mangrove species on the Caribbean coast of Panama," Remote Sensing of Environment, vol. 91, no. 3-4, pp. 432-440, 2004.

[26] M. A. Hardisky, M. F. Gross, and V. Klemas, "Remote sensing of coastal wetlands," BioScience, vol. 36, no. 7, pp. 453-460, 1986.

[27] L. Maynard and D. Wilcox, "Coastal wetlands of the Great Lakes," in State of the Lakes Ecosystem Conference 1996, U.S. Environmental Protection Agency, 1997.

[28] OMNR, "Ontario base map (Wetland polygons, eastern and northern Georgian Bay coast) [computer file]," Ontario Ministry of Natural Resources, 2000, http://www. geographynetwork.ca/website/obm/viewer.htm.
[29] GLCWC, "Coastal Wetland inventory (Polygon data) [electronic file]," Great Lakes Coastal Wetland Consortium, 2004, http://www.glc.org/wetlands/inventory.html.

[30] D. A. Wilcox and J. E. Meeker, "Disturbance effects on aquatic vegetation in regulated and unregulated lakes in northern Minnesota," Canadian Journal of Botany, vol. 69, no. 7, pp. 1542-1551, 1991.

[31] C. Hudon, "Shift in wetland plant composition and biomass following low-level episodes in the St. Lawrence River: looking into the future," Canadian Journal of Fisheries and Aquatic Sciences, vol. 61, no. 4, pp. 603-617, 2004.

[32] R. DeCatanzaro and P. Chow-Fraser, "Relationship of road density and marsh condition to turtle assemblage characteristics in the Laurentian Great Lakes," Journal of Great Lakes Research, vol. 36, no. 2, pp. 357-365, 2010.

[33] R. DeCatanzaro, Factors influencing coastal marsh water quality in Georgian Bay, Ontario, M.S. thesis, McMaster University, Hamilton, Canada, 2010.

[34] A. Wei and P. Chow-Fraser, "Use of IKONOS imagery to map coastal wetlands of georgian bay," Fisheries, vol. 32, no. 4, pp. 167-173, 2007.

[35] J. D. Midwood and P. Chow-Fraser, "Mapping floating and emergent aquatic vegetation in Coastal Wetlands of Eastern Georgian Bay, Lake Huron, Canada," Wetlands, vol. 30, pp. 1$12,2010$.

[36] D. Rokitnicki-Wojcik, A. Wei, and P. Chow-Fraser, "Transferability of object-based rule sets for mapping coastal high marsh habitat among different regions in Georgian Bay, Canada," Wetlands Ecology and Management, vol. 19, no. 3, pp. 223-236, 2011. 

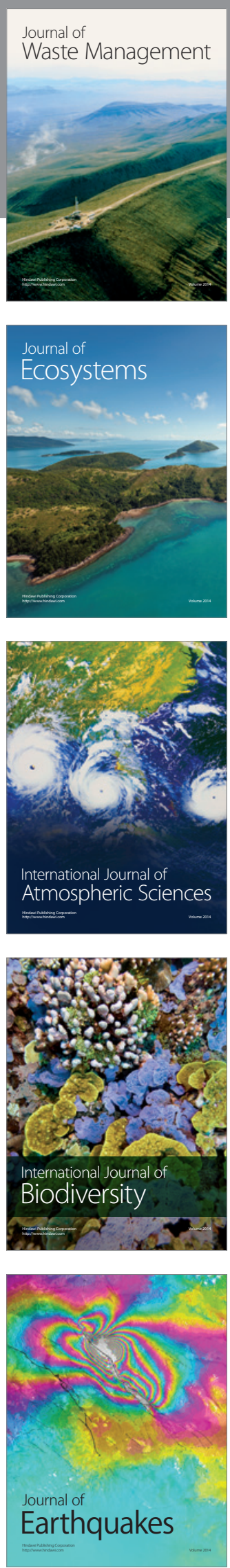
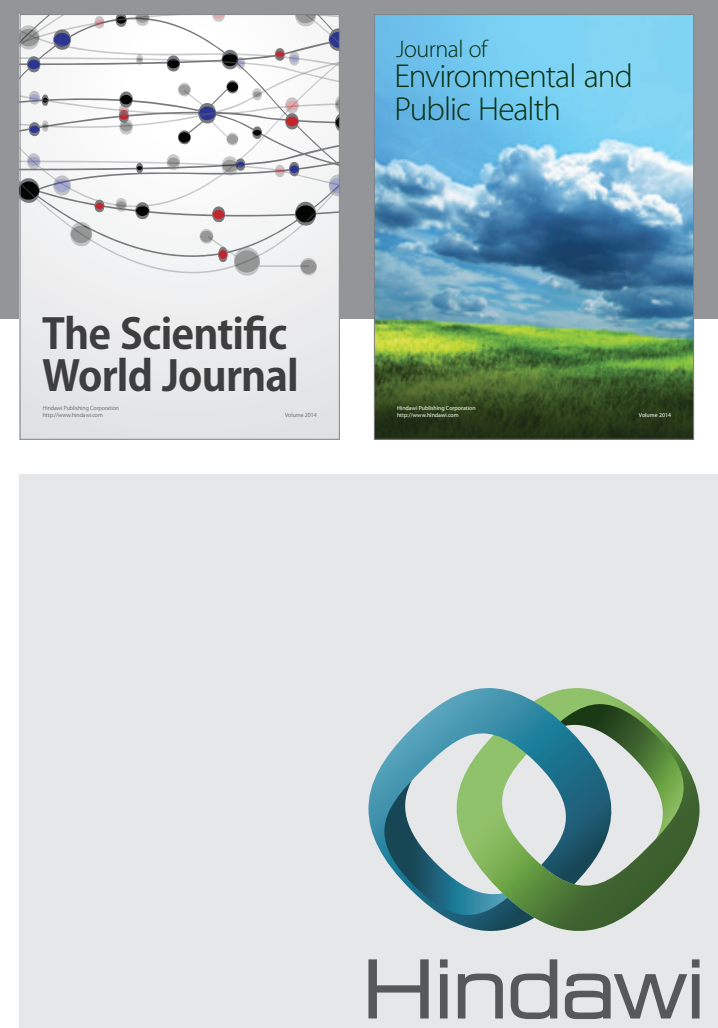

Submit your manuscripts at

http://www.hindawi.com
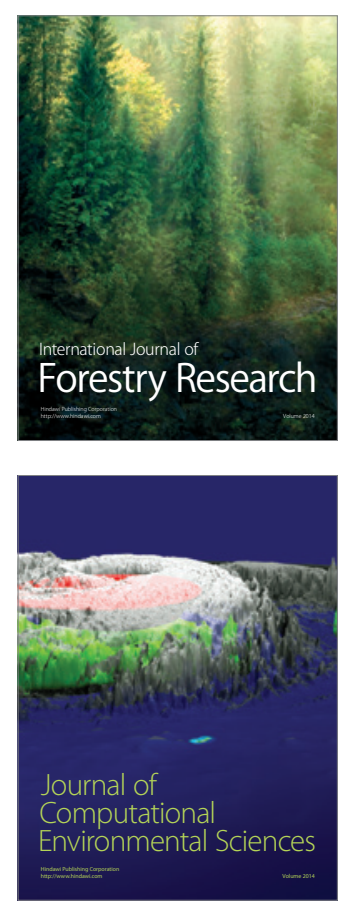
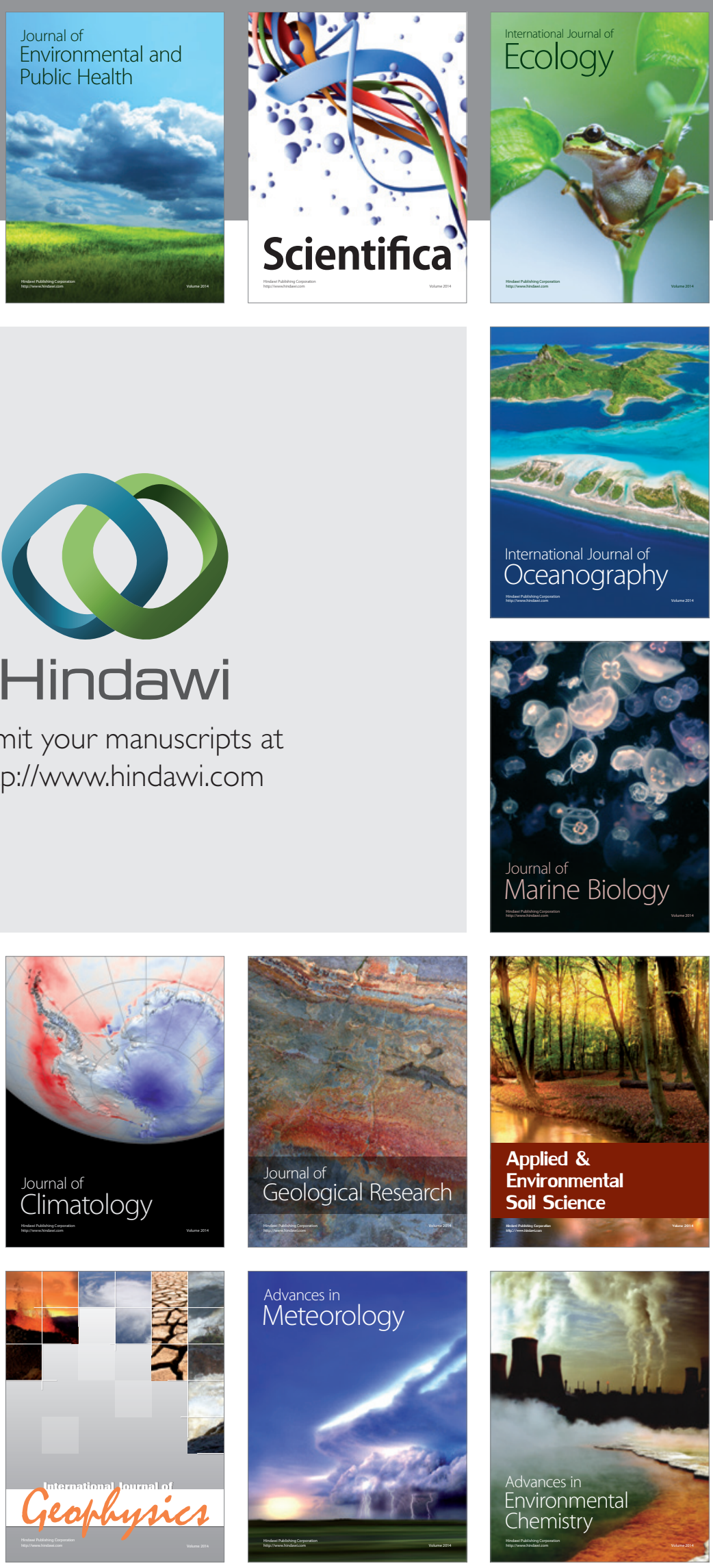